\title{
What is Vulnerability?" A Qualitative Study about the Perception of Vulnerability in Adults and Older Adults
}

\author{
Alethéia Peters Bajotto ${ }^{1,2^{*}}$, Lucas França Garcia ${ }^{3}$ and José Roberto Goldim ${ }^{4}$ \\ ${ }^{1}$ Graduate Program in Medical Sciences, Federal University of Rio Grande do Sul, Brazil \\ ${ }^{2}$ Centro Universitário Franciscano, Brazil \\ ${ }^{3}$ Department of Bioethics and Ethics on Research, Hospital de Clínicas, Porto Alegre, RS/Brazil \\ ${ }^{4}$ Graduate Program in Medical Sciences, Federal University of Rio Grande do Sul, Brazil
}

*Corresponding author: Alethéia Peters Bajotto, Graduate Program in Medical Sciences, Federal University of Rio Grande do Sul, Brazil, Tel: 55 51 98702595; E-mail: aletheia@bajotto.com.br

Received date: July 28, 2016; Accepted date: March 27, 2017; Published date: March 28, 2017

Copyright: ( 2017 Bajotto AP, et al. This is an open-access article distributed under the terms of the Creative Commons Attribution License, which permits unrestricted use, distribution, and reproduction in any medium, provided the original author and source are credited.

\begin{abstract}
Aligned with a global trend, Brazil has been changing demographic profile in recent decades, making this structural phenomenon one of the most important achievements of contemporary society. This social process is not limited to the combined effects of strictly demographic variables and can both create demographic possibilities that enhance the growth of the economy, increasing social welfare, as stressing the economic and social hardships, expanding the serious social inequalities of Brazilian society. In this sense, it is important to read vulnerability from the perspective of research participants, in order to seek the categorization, bringing support for understanding the components of vulnerability allowing the search for strategies to cope with social vulnerability. This paper aims to assess qualitatively, through semi-structured interview, the individual perception about the vulnerability, categorizing the speech of participants and proposing reflections that may enhance the field of social vulnerability. The study is characterized as qualitative content analysis according to Bardin. Nine categories emerged from the speech. The more inference was on account of the category "Health and Disease", with $25 \%$; then with $20 \%$ "Behaviour"; $17 \%$ represented the total of inferences about the "Autonomy"; $15 \%$ related vulnerability to "Fragility"; $9 \%$ on "Family relationships, loneliness"; $4 \%$ related to "Violence"; $3 \%$ to the category "Hunger" and two categories represented $2 \%$ each - "Financial" and "Physical, Age". The personal conception of vulnerability is directly related to disease or illhealth process. The age range, a factor admittedly predisposed to vulnerable, did not have a significant expression in the speech of participants.
\end{abstract}

Keywords: Bioethics; Aging; Vulnerability; Qualitative research

\section{Introduction}

Brazil in recent decades has been changing demographic profile, which is related to the decline in infant mortality and women fertility, increased life expectancy, migration and urbanization. There was a slowdown in the youth population growth rate with the expectation that this segment will continue to grow, although at decreasing rate and that there is an increase in the weight of other age groups, especially the older adult [1].

Given this demographic transition, old age takes on a new dimension in which the "subjective old age," characterized by old age of some people, is replaced by "objective old age", which is a structural phenomenon that concerns the whole society [2].

The ability to question their very existence is a characteristic that identifies the human person as such. Ethical reflections and relationship between people are questions that have been made since the period of Classical Philosophy [3].

In the field of Bioethics, vulnerability is a current issue because vulnerable individuals and groups are subject to exploration, and exploitation is morally wrong because it represents a persistent social relationship in which certain people are used unfairly for the benefit of others [4]. During old age is when vulnerability and temporality are remembered and expressed, which is typical of the human being and that go unnoticed by the vitality that is experienced in juvenile age $[5,6]$.

Bioethics is a complex reflection, it includes the many aspects involved in your object of attention; is interdisciplinary, due to the possibility of having knowledge from different areas of knowledge; and it is shared by using the different interfaces to perform mutually enriching dialogue [3].

Vulnerability is a multidimensional construct that refers to a dynamic context where there is risk for developing health problems, result of inadequate economic, social, psychological, family, cognitive or physical resources. Vulnerability resources help us to understand, for example, the dynamics of poverty - and poverty is not a static condition [7].

In this sense, it is important the vulnerability reading from the research participants perspective, in order to seek the categorization of it, bringing support for understanding the components of vulnerability allowing the search of coping strategies of social vulnerability.

Content analysis is a suitable and widely used method for discourse analysis, because it is a set of communication analysis techniques that aims to overcome the uncertainties and enrich the reading of the data collected [8]. 
The purpose of this paper is to evaluate the individual perception about the vulnerability, categorizing the speech of participants and proposing reflections that may contribute to the field of discussion on social vulnerabilities.

\section{Method}

The study is qualitative and presents the content analysis according to Bardin. The systematic in content analysis proposed by Bardin consisted of three phases: pre-analysis, material investigation and results treatment, inference and interpretation. The goal was to evaluate the individual perception of vulnerability, proposing to each participant a single open question, "What is vulnerability?"

We interviewed 222 research participants, selected in a stochastic way, for convenience, aged 18 years or more. The group of interviewers was composed of two pt undergraduate students (one male, one female and a physiotherapist, $\mathrm{PhD}$ student. Other two undergraduate students transcribed the content and the physiotherapist examined and categorized units. We divided the participants into six different groups, according to age and site of collection.

The subdivision into categories is in the Table 1 :

\begin{tabular}{|l|l|l|l|}
\hline Group & $\mathbf{N}$ & Age group & Interview site \\
\hline 1 & 37 & Older adults & HCPA outpatients \\
\hline 2 & 37 & Older adults & HCPA - inpatients \\
\hline 3 & 37 & Older adults & ESEF - UFRGS \\
\hline 4 & 37 & Adults & HCPA outpatients \\
\hline 5 & 37 & Adults & HCPA inpatients \\
\hline 6 & 37 & Adults & Caregivers \\
\hline
\end{tabular}

Table 1: Distribution of participant groups.

The project that contributed to this originated this paper was approved by the Ethics Board from Porto Alegre Clinic Hospital (GPPG 13-0001) and all information about the study, researchers and contacts, were present in the consent form, signed by the participants as part of the consent process. The interviewers themselves approached subjects, according to the collection site in Table 1 and their willingness was respected throughout the data collection process. Sometimes, participants found themselves alone with the interviewer, especially when it came to outpatients.

Content analysis is a set of communications analysis techniques, using systematic procedures and objectives description of the of message content [9]. The aim of the content analysis is critically to understand the meaning of what is communicated your manifest or latent content, explicit or hidden meanings [10].

Data from open interviews of the participants gave an extensive material, operated in the stages proposed by Bardin: Pre-analysis, material investigation, results treatment, inference and interpretation.

At first, in the pre-analysis phase, a "free reading" of the material was performed, where the first hypothesis, reviewed categories and guiding questions began to emerge. During material investigation the codification was performed - where raw data are aggregated into units and we start the counting procedure. To facilitate this process, the authors performed speech clippings as similarity and after, set up a table that met the incidence of these units of meaning.

The students transcribed the speech of patients in the evaluation documents to Excel program. In this program, systematized categories were chosen to represent the speech of patients, related to the concept of vulnerability, taking as a starting point the expressions that stood out in the statements. This paper followed the standards for qualitative research proposed by the checklist COREQ [11].

\section{Results}

Based on the similarities found in transcription and other content analysis processes, emerged the following categories (Table 2).

\begin{tabular}{|l|l|}
\hline & Categories \\
\hline 1 & Autonomy \\
\hline 2 & Health and disease \\
\hline 3 & Violence \\
\hline 4 & Financial \\
\hline 5 & Hunger \\
\hline 6 & Family relations, loneliness \\
\hline 7 & Frailty \\
\hline 8 & Behaviour \\
\hline 9 & Age, physical \\
\hline
\end{tabular}

Table 2: Identified categories according to the speech of participants.

Below a table represents the distribution of the categories in the sample (Table 3). In the table, we counted the number of inferences from research participants, a number that exceeds the total number of participants. This is because for some individuals the response generated more than one category, such as "Be ill, without family." In this example, we can perceive two categories, "health and disease" (category 2) and "Family relations, loneliness" (category 6).

\begin{tabular}{|l|l|l|}
\hline Category & N & \% \\
\hline 1 & 35 & 17 \\
\hline 2 & 51 & 25 \\
\hline 3 & 8 & 4 \\
\hline 4 & 4 & 2 \\
\hline 5 & 7 & 3 \\
\hline 6 & 19 & 9 \\
\hline 7 & 31 & 15 \\
\hline 8 & 41 & 20 \\
\hline 9 & 5 & 2 \\
\hline $10^{*}$ & 30 & - \\
\hline
\end{tabular}

Table 3: Participants distribution according to categories. 
In this table, it is possible to quantify the distribution of inferences offered by the participants within the categories. The four most significant categories were: Health and disease-25\%; Behavior-with $20 \%$, Autonomy-17\% and Frailty-totaling $15 \%$ of the inferences. The tenth category $\left({ }^{*}\right)$ collected the negatives and answers like "I do not know" and even concepts that do not correspond to any category.

It obtained with the use of NVivo program for Windows 10, which favors the visualization of subtle connections and associations in the discourse of participants (Figure 1).

In this figure, we can observe the frequency of certain words in the speech of the participants and their associations. The size of appearance accuses its representativeness, which means, words such as "health", "disease" and "vulnerable" are words that predominated in the speech of respondents.

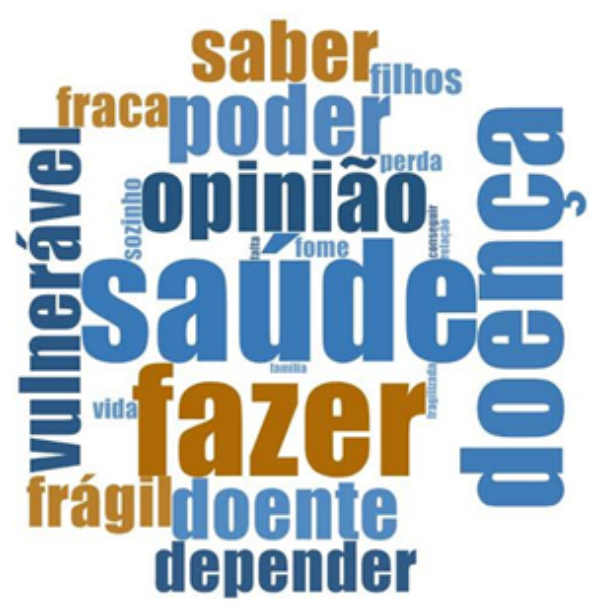

Figure 1: Graphical representation of frequency, in Portuguese.

\section{Discussion}

The speech of the participants regarding the self-perception of vulnerability analyzed in a qualitative way, brings as the first result own organization of categories. The raw material - the speeches - when transcribed and categorized, reveals the foundation where the pillars of this study were raised. The nine categories that emerged from the careful reading and critical responses were: autonomy; health and disease; violence; financial; hunger; family relations or loneliness; frailty; behavior and finally, age, physical.

In each category you can see a face of vulnerability and is on each side that reflection will be guided. Few speeches which could not be assigned to any of the categories and yet, most of it was of participants who responded to the survey question with "I do not know", "I did not understand". Once the interviewer any interference could lead to handling responses, they were instructed not explain the question as acting in this way, the patient would induce a certain judgment, influencing the response. In situations where the research participant asked explanations to the interviewer, this merely encourage you to speak anything knew or thought that could be vulnerable.

A trend related to the discourse of patients is the vulnerability association to health and disease. The World Health Organization (WHO) defines health as not only the lack of disease, but as a state of perfect physical, mental and social well-being. Based on this concept, widely accepted and published by the scientific community, all expressions that could lead to the concept of health or disease were encompassed in this category $[12,13]$.

The "health and disease" was more frequent in discourse, for example: "Not having good health"; "Disease", "Is when you're sick"; "Health". For most of the sample, 25\%, the vulnerability is directly related to health (or lack thereof) or the presence of disease. There is much that the concept of health and disease is being improved, from more simplistic concepts, where health was the absence of disease to the famous definition of WHO, established as a good parameter. Herbert Spencer demand health as a perfect and continuous adaptation of the organism to its environment [14-16]. National and international health agencies do not measure forces to improve the health status of the most vulnerable populations. It is known that by tackling the causes of disease and social inequalities, these individuals fail to appear as vulnerable populations and are to have more chances of reaching adulthood and old age with better quality of life [13].

The eighth category, which represents a "positive or negative behavior", was the second in number of inferences, representing $20 \%$ of the sample. Embraced settings as "Being susceptible to the temptations", "A person who understands", "A person who understand others", "A person who talks too much." This category, despite being the second in terms of representation of the speech, presented confused meaning and that was about moral judgment personnel in relation to a third, putting the vulnerability at a certain distance from itself, like a problem in relation to other.

For Piaget, "all morality is a system of rules and the essence of all morality is to be found in the respect that the individual acquires by these rules [17]". The moral establishes the person, as a way to ensure good life and some identity that group to which it belongs, regardless of geographical boundaries, assumes rules [18].

Autonomy represents the third category in the speech of individuals. In this category were grouped speeches about the restriction of freedom and autonomy, perceived inability to make decisions alone, lack of ability to act without the help of others. The question of "depend on someone" was very marked in the text, promoting "autonomy" as a coherent beacon. According to participants, "Person depends on everything, just do what you're told "; "To be more depending on the other"; "Relying on everyone"; "Not having capacity for yourself, get carried away."

The concept of autonomy is widely used in the biomedical field, since this concept is of utmost importance to the relationship between care team and the patient. The concept on which this category was built states "about yourself, about your body and mind, the individual is sovereign" [19] Autonomy has different meanings, such as selfdetermination, right to freedom, privacy, individual choice, free will [20]. In a study that sought to differentiate autonomy of selfdetermination, the authors from this paper, took as a starting point a community of seniors who had been temporarily discouraged to act without the consent of family to differentiate the concept of autonomy and self-determination. While the former refers to the ability to make decisions, the second term refers to the ability to put the decision into practice, denotes "action [21]".

The Frailty, fourth category, assumed as a state of greater decline associated with reservation and function, resulting in reduced ability to cope with everyday or acute stressors [22]. It was grouped in this category the perception of participants who used this term with 
definition of vulnerability or have referred to physical limitations, difficulties or disabilities. This term is also used by professionals of gerontology and geriatrics to indicate the condition of older people who are at high risk for falls, hospitalization, disability, institutionalization and death. However, the vulnerability of the relationship with age has its own category. It also appears defined as a clinical syndrome characterized by reduction of the reserve and decreased resistance to stressors, and result of the cumulative decline in physiological systems and cause vulnerability to adverse conditions, such as diseases, environmental changes and accidents [22,23]. "Being exposed to any situation"; "More fragile"; "Show some weaknesses on certain occasions" are examples of discourse that originated this category.

The other categories did not obtain as large number of inference as the others, but they are issues from important spheres in everyday life of this sample, therefore, deserves to discussion. The category that combined references to family relationships and/or loneliness emerged speeches that articulates lack or fear to loss of a loved one (such as children or spouse) and, with the "feel alone". Studies that assess the quality of life in elderly already point in that direction: the quality of life related to social support, social interaction and less specifically related to health or absence of morbidity [24-26] Vulnerability to these participants, regardless of what age, is not to be able to rely on a social network support, mainly family. Some examples are "I am very vulnerable when my grandson travels"; "Being with no one, alone and not to do things right."

Violence is understood as any action addressed to another person, where harming, hurting, frightening or insulting, drives a person to act against his will or not taking any action at will [27]. In the speech of individuals, violence emerges as a generic term, unspecified, more related to the fear of going out and being surprised by an act prejudicial to its security: "To be attacked and cannot defend themselves," "Today is the lack of security that the guy lives because they cannot go out alone Health business". In the last example, we find a speech that was classified as belonging to two categories.

Financial issues also figured the categories, born of the need to group the speech of patients in relation to a state where financial reserves are short. Hunger, considered a more severe type of food insecurity is defined as the direct sense of discomfort or pain of not having enough to eat [28]. In this context, the research participants related "hunger" to "vulnerability": quoting as vulnerability personal concept those who have nothing/not enough to eat.

Chronological age, to the surprise of the researchers, was less related to vulnerability, only $2 \%$. In this category are grouped discourses that address the limitations imposed by chronological age, for example, be "old" and "get older." The surprise arises because individuals 60 years or more, by definition, are considered vulnerable. Thus, the weak association of old age with the vulnerability is a finding that contributes to the paradigm shift of "vulnerable elderly without ability." The prioritization of the most vulnerable groups of a population is crucial in an attempt to minimize the effects of social inequality in our country [29]. Equity, a guiding principle of the Single Brazilian health system, implies that ideally everyone should have a fair opportunity to get full health potential and no one should be disadvantaged from achieving the potential, if it possible to avoid. In short, suggests that different people should have access to sufficient health resources for their health needs [30].
The visual representation recognized the categorization. Visually, we can assign higher occurrence to words that appear in larger, as well as how close they are, also indicates a relationship. "Health", "disease", "vulnerable", "power", "sick" and "dependent", all in shades of blue, establish a direct relationship with three of the four categories with the highest number of inferences: "health and disease", "autonomy" and "frailty". Health, disease and vulnerable establish a point of contact in the graphical representation, which also suggests that in addition to a significant occurrence in the discourse of patients, those words still relate within the speeches.

\section{Final Considerations}

In the sample, which are disparate everyday situation-from adults and elderly patients admitted to general hospital or physically activethe vulnerability concept is directly related to disease or lack of health.

The issue of vulnerability associated with behavior, the result of moral judgment, also had a significant numerical expression. On the other hand, this category incorporated various positions, making it difficult to specify the significance of this category precisely. Autonomy also occupied a prominent place in the speeches. The autonomy is all about the dependent-widely-of respondents toward someone. The vulnerability lies in the act of relying on someone for survival, as naturally early in life, takes a pejorative paper when referring to adulthood or older adults.

Frailty, used as a synonym of vulnerability, followed this trend also in this study. The word "frailty" appeared significantly in the statements and generally towards synonym for vulnerability. Another feature of vulnerability is not able to rely on a network of social support, mainly family. The age factor, did not obtain a significant expression in the speech of participants.

\section{References}

1. Saúde M da (2010) Diretrizes Nacionais para a Atenção Integral à Saúde de Adolescentes e Jovens na Promoção, Proteção e Recuperação da Saúde pp.132.

2. Rodriguez Cabrero G (1989) La Participación social de las personas mayores.

3. Goldim JR (2009) Bioética complexa: uma abordagem abrangente para o processo de tomada de decisão. Rev da AMRIGS 53: 58-63.

4. Macklin R (2003) Bioethics, vulnerability, and protection. Bioethics 17: 472-486.

5. Simões JA (2010) Reflexão bioética Sobre a situação do idoso e sua família. Acta Med Port 23: 483-492.

6. Wilde MH (2003) Life with an indwelling urinary catheter: the dialectic of stigma and acceptance. Qual Health Res 13: 1189-1204.

7. Bank AD (2012) Handbook on Poverty and Social Analysis A Working Document. Asian Development Bank.

8. Ferreira M, Quadros Loguecio R de (2014) A análise de conteúdo como estratégia de pesquisa interpretativa em educação em ciências. Revel-Rev Educ Ling E Lit 6: 33-49.

9. Bardin L (1977) Análise de conteúdo. 70th (edn.) Lisboa.

10. Vergara SC (2011) Réplica 2-análise de conteúdo como técnica de análise de dados qualitativos no campo da administração: potencial e desafios. Rev Adm Contemp 15: 761-765.

11. Tong A, Sainsbury PCJ (2007) Consolidated criteria for reporting qualitative research (COREQ): a 32-item checklist for interviews and focus groups. Int J Qual Heal Care 19:349-357.

12. Rouquayrol A (2013) Epidemiologia e saúde. (7th edn.) São Paulo, pp. 736. 
Citation: Bajotto AP, Garcia LF, Goldim JR (2017) What is Vulnerability?" A Qualitative Study about the Perception of Vulnerability in Adults and Older Adults. J Clin Res Bioeth 8: 1000299. doi:10.4172/2155-9627.1000299

Page 5 of 5

13. Irwin A, Scali E (2010) Action on the social determinants of health: learning from previous experiences. Organización Mundial de la Salud.

14. Campos MO, Neto JFR (2002) QUALIDADE DE VIDA: UM INSTRUMENTO PARA PROMOÇÃO DE SAÚDE. Endocrinol Metab 46: 232-240.

15. Spencer H (1966) Herbert Spencer's Sociology: A Study in the History of Social Theory. Atherton, New York.

16. Oliveira RR De (2014) Dos conceitos de regulação às suas possibilidades. Saúde e Soc 23: 1198-1208.

17. Piaget J (1977) O juízo moral na criança. São Paulo: Mestre Jou.

18. Genro B (2013) Consultorias De Bioética clínica区: Da Teoria, UFRGS, À Prática.

19. John Stuart Mill: On Liberty. Boston: Collier.

20. Beauchamp T, Childress J (1978) Principles of biomedical ethics. Oxford University Press, New York.

21. Bajotto AP, Goldim JR (2011) Case-Report: Autonomy and Self Determination of an Elderly Population in South Brazil. J Clin Res Bioeth 02: 2-4.

22. Teixeira INDO (2006) Percepções de profissionais de saúde sobre duas definições de fragilidade no idoso * The perception of health professionals of two definitions of frailty in elderly people. Heal (San Fr 1181-1188.

23. Andrew MK, Mitnitski AB, Rockwood K (2012) Social vulnerability, frailty and mortality in elderly people. PLoS One 3: e2232.
24. Bajotto AP, Goldim JR (2011) Avaliação da qualidade de vida e tomada de decisão em idosos participantes de grupos socioterápicos da cidade de Arroio do Meio, RS, Brasil. Rev Bras Geriatr e Gerontol 14: 753-761.

25. Pinto MF, Barbosa DA, De Lucena Ferreti CE, De Souza LF, Fram DS (2009) Qualidade de vida de cuidadores de idosos com doença de Alzheimer. ACTA Paul Enferm 22: 652-657.

26. Inouye K, Barham EJ, Pedrazzani ES, Pavarini SCI (2010) Percepções de suporte familiar e qualidade de vida entre idosos segundo a vulnerabilidade Social. Psicol Reflexão e Crítica 23: 582-592.

27. Flåm AM, Handegård $\mathrm{BH}$ (2015) Where is the Child in Family Therapy Service After Family Violence? A Study from the Norwegian Family Protection Service. Contemp Fam Ther 37: 72-87.

28. Niclasen B, Molcho M, Arnfjord S, Schnohr C (2013) Conceptualizing and contextualizing food insecurity among Greenlandic children. Int J Circumpolar Health 72: 1-12.

29. Issler RMS, Giugliani ERJ (1997) Identificação de grupos mais vulneráveis à desnutrição infantil pela medição do nível de pobreza. J Pediatr 73: 101-105.

30. Lucchese PTR (2003) Eqüidade na gestão descentralizada do SUS: desafios para a redução de desigualdades em saúde. Cien Saude Colet 8 : 439-448. 